\title{
Entre la filosofía y la poesía: Heidegger y Hölderlin
}

\section{Between philosophy and poetry: Heidegger and Hölderlin}

\author{
María Teresa Stuven Vattier ${ }^{1}$ \\ 'Pontificia Universidad Católica de Chile, Santiago, Chile. Profesora Asociada. Licenciada en Filosofía, Pontificia \\ U. Católica de Chile. \\ mstuvenv@uc.cl
}

\section{Resumen:}

El núcleo del pensamiento de Martin Heidegger está constituido por el problema del ser. El filósofo considera central este tema, pues la filosofía anterior había planteado erróneamente la pregunta acerca del ser y, por tanto, ésta no se había podido resolver en forma acertada. Su principal obra, Ser y tiempo (1927), plantea este problema en medio de una Modernidad apartada de la cuestión ontológica. En esta obra Heidegger no sólo aborda la pregunta por el Ser, sino que reflexiona y analiza lo sucedido en el hombre contemporáneo con el olvido del Ser. Aun cuando él no quiso hacer una antropología, Ser y tiempo es una profunda reflexión acerca del hombre del siglo veinte, abrumado por la técnica y el pensamiento calculador. El filósofo propone una nueva manera de habitar en el mundo, dentro del cual el Ser tenga cabida. Este modo de existencia es la propiedad o autenticidad frente a la impropiedad o inautenticidad, modos de ser del Dasein cotidiano.

Desde los años 30, Heidegger tiene un vuelco en su pensar (Kehre) y reflexiona acerca de la poesía y el Ser. Esta relación no es sólo patrimonio de los filósofos, es también de los poetas. Dos son las obras principales de Heidegger acerca de la poesía: Hölderlin y la esencia de la poesía, un escrito de 1936, y Poéticamente habita el hombre, conferencia de 1951. En este trabajo nos referiremos a esos textos, en los cuales, pensamos, se amplía la propuesta de Ser y tiempo respecto a la vinculación el Dasein con el Ser, ahora desde el habitar poético frente al habitar impoético.

Palabras Clave: Poesía; Ser; Lenguaje; Habitar; Dios; Medida humana; Voz del pueblo.

\section{Abstract:}

The core of Martin Heidegger's thought is constituted by the problem of being. The philosopher considers this issue central, since previous philosophy had erroneously posed the question about being and, therefore, it had not been able to be resolved correctly. His main work, Being and Time (1927), poses this problem in the midst of a Modernity removed from the ontological question. In this work, Heidegger not only addresses the question of Being, but also reflects and analyzes what happened in contemporary man with the forgetfulness of Being. Even though he did not want to make an anthropology, Being and Time is a profound reflection on the man of the twentieth century, overwhelmed by technique and calculating thinking. The philosopher proposes a new way of inhabiting the world, within which the Being has a place. This mode of existence is property or authenticity in the face of impropriety or inauthenticity, ways of being of everyday Dasein.

Since the 30s, Heidegger has a turn in his thinking (Kehre) and reflects on poetry and the Being. This relationship is not only the heritage of philosophers, it is also of poets. There are two main works by Heidegger about poetry: Hölderlin and the essence of poetry, a 1936 writing, and Poetically inhabits man, a 1951 lecture. In this work we will refer to those texts, in which, we think, The proposal of Being and time is expanded with respect to the link between Dasein and Being, now from poetic living versus impoetic living.

Keywords: Poetry; Being; Language; Inhabiting; God; Human measure; Voice of the people. 


\section{Hölderlin y la esencia de la poesía}

Heidegger se propone investigar aquello que constituye específicamente a la poesía como tal. Para elaborar "un concepto general, válido indiferentemente para toda especie de poesía" (Heidegger, 1944, p. 14). Se debieran comparar las obras de varios poetas, como también las de un género poético con otros. Sin embargo, señala Heidegger: algo válido para todo lo particular es siempre lo indiferente: "lo general es así una 'esencia' que no llega a ser jamás esencial" (Heidegger, 194, p. 14).

¿Por qué se escoge entonces sólo a un poeta: Hölderlin?

... únicamente porque lo que forma el soporte de la poesía de Holderlin es esta determinación poética que consiste en poetizar expresamente la misma esencia de la poesía. Hölderlin es en un sentido privilegiado el poeta del poeta. Por esto, él nos fuerza a la decisión. (Heidegger, 1944, p. 14).

Heidegger no analizará toda la poesía del poeta; escogerá cinco leitmotives (sentencias) referentes a la posición del poeta frente a la poesía, los cuales en su conexión interna, justificarán de sobra la elección realizada.

\section{Leitmov |}

“...poetizar (...)'La ocupación es ésta la más inocente de todas"' (citado en Heidegger, 1944, p. 14).

Hölderlin escribe en 1799 estas palabras a su madre La poesía, le dice consolándola, es como un sueño, no una realidad; queda contemplativa en el reino de la imaginación. Es como "un juego de palabras" (Heidegger, 1944, p. 14); no es una realidad, no hace daño, es un puro hablar. No tiene la seriedad de una decisión, la cual siempre compromete de una u otra manera. Poesía es lenguaje puro, algo sin peligro.

\section{Leitmotiv ||}

“... porque aún el lenguaje, el más peligroso de todos los bienes, le ha sido dado al hombre (...) para que testimonie lo que él es ..." (Heidegger, 1944, p. 15).

Parece contradictorio con lo dicho anteriormente: el lenguaje, es peligroso y ha de testimoniar el ser del hombre. ¿Qué es el hombre? Él hombre tiene lo más divino: razón y libre arbitrio; es semejante a los dioses. La atestación del hombre no es una acción añadida a él, sino la constitución misma de su existencia. ¿Qué debe atestiguar? "Su pertenencia a la Tierra (...) que consiste en ser heredero y aprendiz en todas las cosas" (Heidegger, 1944, p. 15). Pero, las cosas están en conflicto. Lo que las separa y, a la vez las reúne ${ }^{1}$ es lo que Hölderlin llama "una esencial intimidad" (Heidegger, 1944, p. 16). La manifestación de la pertenencia a esta intimidad se produce por la creación de un mundo, como también por su destrucción. Consiste en dar testimonio de esta pertenencia al Ser como totalidad. Constituye una libre decisión del hombre. Con ello el ser humano realiza la autenticidad de su existencia, la cual

\footnotetext{
${ }^{1}$ Resuena el "logos" de Heráclito, filósofo presocrático, a quien Heidegger conocía muy bien. Légein = reunir; logos: el que reúne a los contrarios.
} 
se efectúa como Historia. Para que haya historia, el hombre necesita del lenguaje y, por tanto, es éste un bien para él.

Pero, el lenguaje es un peligro porque amenaza al Ser. "La tarea del lenguaje es revelar el ser como tal en la obra y garantizarlo en ella" (Heidegger, 1944, p. 16); sin embargo, puede ser campo de error y pérdida del ser. Para ser comprendido tiene que hacerse común y en este propósito la palabra puede dar la apariencia de lo esencial; puede ser inauténtica, sisponemos del lenguaje para comunicar (experiencias, afectos, acciones, etcétera) y, en este sentido, es un bien, pero su esencia no se agota en ello (Heidegger, 1944, p. 16). "El lenguaje no es solamente un instrumento que [se] (...) posee entre muchos otros, (...) es lo que, en general, y ante todo, garantiza la posibilidad de encontrarse el hombre en medio de lo abierto del ser que está siendo" (Heidegger, 1944,. p. 17).

Solamente donde hay lenguaje hay 'mundo', o sea, ese "círculo (...) cambiante de decisión y de empresa, de acción y de responsabilidad, como también de arbitrariedad, de tumulto y de caídas, y de extravíos" (Heidegger, 1944, p. 17). El lenguaje "es lo que depara la suprema posibilidad de ser del hombre" (Heidegger, 1944, p. 17). Es desde esta esencia del lenguaje que podrá captarse la esencia de la poesía.

\section{Leitmotiv III}

"El hombre ha experimentado mucho

De los dioses ha nombrado mucho

Desde que somos un diálogo

$Y$ desde que podemos oírnos los uno a los otro" (citado en Heidegger, 1944,p. 17)

El ser del hombre tiene su fundamento en el lenguaje y éste se actúa únicamente en el diálogo. El lenguaje es un mediador entre unos con otros y actúa auténticamente sólo en el diálogo" Poder oír es el supuesto de poder hablar unos con otros, "coexisten desde el origen" (Heidegger, 1944, p. 17).

"Somos un diálogo" (Heidegger, 1944, p. 18). La unidad del diálogo significa que cada vez en la palabra esencial sea revelado el Uno y Mismo sobre el cual nos unimos, en razón del cual nosotros somos Uno y también auténticamente nosotros mismos. El diálogo y su unidad soportan de nuestra existencia (Heidegger, 1944, p. 18).

Si Holderlin dice "desde" que somos diálogo quiere decir que, no porque haya lenguaje, hay diálogo. Para que haya diálogo "la palabra esencial ha de quedar relativa al Uno y al Mismo" (Heidegger, 1944, p. 18) - cf. Heráclito: No a mí, sino al Logos escuchando, sabio es con-decir que todo es Uno. (Rivera, 2006)-. Pero, éstos se revelan sólo en alguna cosa que permanezca, es decir, "cuando brillan la constancia y la presencia" (Heidegger, 1944, p. 18). Únicamente cuando el hombre se coloca en lo presente de algo que persiste se expone a lo mudable. "... pero esto se produce en el instante en que el tiempo se abre en sus extensiones" (Heidegger, 1944, p. 18). Es en el desgarrador acontecer de un presente, pasado y futuro, cuando subsiste la posibilidad de unirse a alguna cosa que persiste. Un diálogo somos nosotros mismos desde que hay tiempo. Desde que éste es llevado a existir y persistir, somos históricos. Ser un diálogo y ser histórico son la misma cosa. En el momento en que el lenguaje se historializa como diálogo, los dioses han sido nombrados y aparece un mundo. Pero los dioses vienen a la palabra sólo cuando nos interpelan y nosotros 
respondemos libremente a ellos, aceptándolos o rehusándolos, jugándonos en ello nuestro destino. La presencia de los dioses y la aparición del mundo no son consecuencia del advenimiento del lenguaje; son, más bien, simultáneos. Es "en la denominación de los dioses y en el hecho que el mundo devenga palabra en lo que consiste el diálogo auténtico que somos nosotros mismos" (Heidegger, 1944, p. 18).

Termina el Leitmotiv III preguntando: ¿Quiénes aprehenden lo permanente en medio de la fugacidad del tiempo? ¿Quién es el que denomina a los dioses?

\section{Leitmotiv IV}

"Pero lo que permanece los fundan los poetas" (citado en Heidegger, 1944, p. 19)

"La poesía es fundación por la palabra y en la palabra" (Heidegger, 1944, p. 19). ¿Qué es lo fundado? Lo que permanece no es siempre lo fundado; ello debe ser llevado a persistir contra lo que fluye y "lo simple debe ser arrebatado a la confusión" (Heidegger1944, p. 19). Es el Ser, que ha de ser puesto al descubierto, para que lo existente aparezca, puesto que nunca se deja extraer de lo efímero, ni de lo existente dado. El Ser no es nunca un "siendo". Lo que permanece, el Ser, es lo confiado a los poetas. "El poeta nombra a los dioses, nombra todas las cosas en lo que ellas son ..." (Heidegger, 1944, p. 19).

Aquí Heidegger hace ver lo distinto del pensamiento calculador y el pensamiento científico que nunca dan con el ser ni con la esencia de las cosas. Es preciso que el ser y lo esencial "sean libremente creados, puestos y dados" (Heidegger, 1944, p. 19) "...la esencia de las cosas pasa a la palabra para que entonces las cosas empiecen a lucir" (Heidegger, 1944, p. 19). "El lenguaje es lo que en general y, ante todo, garantiza la posibilidad de encontrarse el hombre en medio de lo abierto del ser..." (Heidegger, 1944, p. 19). Pero, al mismo tiempo a la existencia humana le sucede algo:

... la existencia humana accede a una relación fija y es asentada sobre un fundamento. El 'decir' del poeta es fundación no sólo en el sentido de una libre donación, sino igualmente en el sentido de que asienta y asegura sobre su fundamento, la existencia humana. (Heidegger, 1944, pp. 19-20)

\section{La poesía y la persona del poeta}

\section{Leitmotiv V}

En el poema: "Amable azul..." declara Holderlin:

"Lleno de méritos, sin embargo, es poéticamente

Como el hombre vive sobre esta tierra" (citado por Heiddeger, 1944, p. 20)

"Lleno de méritos": lo que el hombre logra y persigue con su trabajo es merecido por su propio esfuerzo. Esto no concierne a la esencia del habitar sobre la tierra ni a la raíz de la existencia humana. "Habitar poéticamente' quiere decir: Estar en la presencia de los dioses y ser afectado por la presencia esencial de las cosas (...) significa decir al mismo tiempo que ella en cuanto fundada (es decir, puesta sobre una base) no es un mérito, sino donación" (Heidegger, 1944 , p. 20). "La poesía no es simple ornamento de la existencia ni (...) pasatiempo (...) es el 
fundamento que soporta la Historia, y por esto no es sólo una manifestación de la cultura ..." (Heidegger, 1944, p. 20).

Pero la poesía no es un juego inofensivo, ni un entusiasmo de momentos ¿Como se junta esta afirmación con "la ocupación más inocente?" Estas dos frases que resumen la esencia total de la poesía las verá Heidegger en relación a la poesía y al poeta. Con respecto a la poesía, se ha comprendido que ella no recibe el lenguaje como su materia, sino ella empieza por hacer posible el lenguaje. La poesía es el lenguaje original de un pueblo. La esencia del lenguaje tiene que ser comprendida por la esencia de la poesía, ya que la lengua primordial es la poesía como institución del ser: ella es lo originario que nombra el ser y el lenguaje, lo derivado.

Poniéndose ahora en el lugar del poeta: ¿Qué peligro representa la poesía para el poeta? Escribe Hölderlin a un amigo:

¡Amigo mío! el mundo está más claro que nunca y más grave! Me alegro de lo que sucede, estoy contento como el Padre antiguo y sagrado hubo sacudido con mano apacible a través de las nubes enrojecidas, los relámpagos que bendicen... Porque entre todo lo que puedo ver de Dios, este signo se ha hecho mi signo predilecto. Antes podía exultarme por una verdad nueva, por una visión mejor de lo que hay por encima de nosotros y en torno nuestro: ahora temo que me ocurra finalmente a mí lo que al viejo Tántalo que recibió de los dioses más de lo que podía digerir. (citado en Heidegger, 1944, p. 21).

"El poeta está expuesto a los rayos del Dios" (Heidegger, 1944, p. 19). Es lo que se expresa en el siguiente poema que representa la más pura esencia de la poesía:

Como un día de fiesta, cuando un campesino

Sale a la mañana para ver la campiña (...)

Sin embargo, nos conviene bajo las tempestades de Dios,

Los poetas, jvosotros!, quedar en pie, con la cabeza descubierta

Con nuestra propia mano tomar el relámpago del Padre,

El Padre mismo y ofrecer al pueblo

El don celeste envuelto en el canto. (citado en Heidegger,1944, p. 21)

Poco tiempo después, ya atacado por la locura y residiendo en la casa de su madre, vuelve a escribir a su amigo:

El elemento inmenso, el fuego del cielo, la naturaleza, su limitación y el silencio de los hombres, su vida en la naturaleza, su limitación y su satisfacción me han asaltado sin cesar, y como se repite de los héroes, puedo muy bien decir de mí igualmente que Apolo me ha herido. (citado en Heidegger, 1944, p. 22)

La poesía tiene la apariencia de un juego, esta apariencia inofensiva protege al poeta, pero la realidad es que "el hombre queda concentrado sobre el fondo de la existencia humana" (Heidegger, 1944, p. 22). El poeta ha de resistir este abismo y ofrecer su canto al pueblo.

"La poesía despierta la aparición de lo irreal, y del sueño frente a la realidad ruidosa y palpable en la que creemos estar. $Y$, sin embargo, lo real es todo lo que el poeta dice y lo que él asume del 
ser" (Heidegger, 1944, p. 22). Ahora bien, la palabra poética posee su fuerza sólo cuando los dioses impulsan a hablar. Ellos no hablan directamente, sino por medio de signos. El poeta recoge estos signos para presentarlos a su pueblo. La institución del ser está ligada a los signos de los dioses. Y al mismo tiempo no es más que la interpretación de la 'voz del pueblo' (Heidegger, 1944, p. 23-24). Es por eso que Holderlin acude a las memoriales leyendas, en las cuales el pueblo concentra su memoria, "su pertenencia a lo siendo en su totalidad" (Heidegger, 1944, p. 23). Pero esta voz a veces calla, no es capaz de decir lo propio y tiene necesidad de otros que la interpreten. El poeta se mantiene entre los dioses y la voz del pueblo. Es en esta dualidad donde queda establecida su existencia, dualidad a la que el poeta alemán consagra su palabra. Es por ello que Hölderlin es "el poeta de los poetas" “No debemos reconocer (...) que el pensamiento de este poeta está presionado por un pulso desbordante hasta el fundamento y corazón del Ser? “(Heidegger, 1944, p. 24).

La esencia de la poesía no se dice como valor universal, pertenece a un determinado tiempo, pero el poeta no se conforma con este tiempo. Instituyendo de nuevo la esencia de la poesía Hölderlin funda un tiempo distinto: el de los dioses por venir y de los dioses idos. El tiempo de los dioses que se han ido, porque no pueden habitar en este mundo atrapado por el pensamiento calculador y la adoración por la ciencia. Entonces Hölderlin proclama el Dios por venir.

"Pero él se mantiene firme en la Nada de esta noche. Persistente en sí mismo como el supremo solitario que individualiza su destino propio, el poeta trabaja de verdad para su pueblo y, por eso, trabaja en verdad" (Heidegger, 1944, p. 24). Es tiempo de la indigencia. Es lo que se describe en el poema con que Heidegger termina su texto:

¡Pero, amigo! Llegamos demasiado tarde. Ciertamente los dioses viven,

Pero por encima de nuestras cabezas, en otro mundo,

Sin fin ellos se agitan y parecen poco atentos

Al hecho de que vivamos, así los dioses nos tratan con cuidado, Pues un vaso frágil no puede siempre contenerlos.

(...)

Que dormir sería mejor que estar así sin compañero

$Y$ que perseverar así. Y qué hacer y qué decir cuando se espera

No lo sé; ¿y para que poetas en tiempos de indigencia?

Pero ellos son, dices tú, como los sacerdotes sagrados de Dionisos que de país en país erraban en la noche sagrada. (citado en Heidegger, 1944, p. 25)

\section{Poéticamente habita el hombre}

El habitar está hoy definido por la necesidad habitacional, por el trabajo, el éxito, las diversiones. No queda espacio para lo poético. El título de este ensayo de Heidegger corresponde al verso del poema En el amable azul de Hölderlin, citado en el texto anterior de Heidegger. En esta conferencia se quiere relacionar el habitar con la poesía, no como un accesorio. Esta frase dice: "...el poetizar, deja ante todo al habitar ser un habitar (...) poetizar es, en cuanto dejar habitar, un construir" (Heidegger, 1960, pp. 78 y79). 
¿En qué consiste la esencia del habitar y del poetizar?

Para aclararlo hay que dejar hablar al lenguaje; éste propiamente habla. "El hombre (...) habla solamente en cuanto corresponde (...) al lenguaje, oyendo su requerimiento (...) El lenguaje 'empieza y termina por hacernos señas de la esencia de una cosa'"'(Heidegger, 1960, p. 79). Pero es sólo en el poetizar que el hombre oye su requerimiento. En el poema El amable azul "Lleno de méritos" es la frase que antecede a "pero poéticamente habita el hombre":

Si la vida no es más que esfuerzo, ¿puede un hombre

alzar la vista y decir: así

quiero yo también ser? Sí.

(...)

Pleno de méritos, más poéticamente habita el hombre sobre la tierra. Pero no es más pura

La sombra de la noche con las estrellas,

Si así pudiera yo decir, tal como

El hombre, a quien se le llama imagen de la divinidad.

¿Hay una medida sobre la tierra? No hay

Ninguna. (citado en Heiddeger, 1960, p. 83)

La vida implica esfuerzo y el hombre lo hace para alcanzar méritos, es decir, porque siente que ello le traerá plenitud a su habitar en esta tierra. Sin embargo, también puede elegir habitar con la vista al cielo y permanecer, a la vez, en el abajo (Heidegger, 1960, p. 83), midiendo "cabo a cabo el 'entre' del cielo y la tierra" (Heidegger, 1960, p. 83). El hombre no asume ocasionalmente esta medición, "sino que, en tal medición, de cabo a cabo, el hombre es ante todo recién hombre. Desde siempre él se ha medido con lo celestial, con la divinidad, incluso Lucifer ha sido celestial.

Únicamente en cuanto re-mide su habitar de ese modo, puede ser a la medida de su esencia. Este re-medir que mide en toda su extensión este 'entre' que reúne el cielo y la tierra es la esencia de lo poético del habitar. El habitar del ser humano reposa en el re-medir de la dimensión - re-medir que alza la vista - a la que pertenece tanto el cielo como la tierra. (Heidegger, 1960, p. 84)

Cada hombre despliega su esencia en cuanto es mortal y él muere continuamente, mientras permanezca en esta tierra. A pesar de ser mortal, su habitar esencial reside en lo poético, es decir, en la medida con la divinidad.

¿Cómo demostrar que Hölderlin piensa así? Todo se puede demostrar, señala Heidegger, sobre la base de presupuestos, según como éstos sean puestos. Aquí sólo basta con prestar atención - cosa difícil - a la palabra del poeta. Hölderlin se pregunta por la medida con que el hombre se mide. Y responde: es la divinidad.

Pero, ¿podemos conocer a Dios? ¿No es Dios desconocido? Evidentemente no, porque si así fuera no podría ser medida. Para Holderlin "Dios es, en cuanto el que Él es, desconocido y en cuanto es este desconocido, es precisamente la medida del poeta" (Heidegger, 1960, p. 85) Pero, ¿cómo puede ser medida un Dios desconocido? En cuanto Dios es el que es, debe permanecer desconocido. Y, a pesar de esto, es la medida. "La patencia (...) de Dios 
y no El mismo es misteriosa" (Heidegger, 1960, p. 85). Se pregunta, entonces nuestro poeta, si acaso Dios es patente como el cielo y responde así en los versos precedentes a "... poéticamente habita ...":

Mientras la pureza,

la amabilidad perduren junto al corazón, no se mide

Desventuradamente el hombre

Con la Divinidad ¿Es Dios desconocido?

¿Es Él tente como el cielo? Esto

más bien lo creo. (citado en Heidegger, 1960, p. 85)

"La medida consiste en el modo como el Dios desconocido que permanece en cuanto tal, es patente mediante el cielo" (Heidegger, 1960, p. 85). Este aparecer consiste en un develar que deja ver aquello que oculta. No porque lo arranque de su ocultamiento, "....sino sólo porque protege lo oculto en su ocultarse. Así aparece el Dios desconocido mediante la patencia del cielo. Este aparecer es la medida en la cual se mide el hombre". (Heidegger, 1960, p. 85).

Esta medida no es algo fácil de concebir para la opinión común de los mortales, "... incómodo para el equitativo omnicomprender del diario opinar que gustoso se afirma como el padrón de medida de todo pensar y conocer" (Heidegger, 1960, p. 86). Tampoco para la ciencia y la técnica, las cuales operan de otro modo: apoderándose de las cosas, manipulando la realidad para extraer el máximo de beneficios de los recursos del planeta, aun a costa de éste. La toma de medida del poetizar "... acontece en un tomar que jamás se apodera de la medida, sino que la toma en el percibir en conjunto, que permanece en un oír" (Heidegger, 1960, p. 86), en una receptividad de lo que se ofrece como tal.

Esta medida tan extraña para los contemporáneos ha de ser confiada a nosotros, coparticipada mediante el poetizar, porque "mide en toda su extensión la esencia del hombre (...).'Sobre' y 'debajo' se pertenecen uno a otro. Su uno-en-otro (...) es la medida que recorre el hombre en tanto que cuanto es terrenal" (Heidegger, 1960, p. 86).

"Porque él (...) es en cuanto soporta la dimensión, su esencia ha de ser re-medida cada vez. Para ello la esencia requiere de una medida, que de una vez toque la dimensión total" (Heidegger, 1960, p. 86). Ver esta medida como medida, medirla-en toda su extensión y tomarla como medida, es el poetizar "... esto para el habitar del hombre" (Heidegger, 1960, p 86). Poetizar es el medir por excelencia.

Parece extraño que el poetizar sea un medir, si se toma éste en su sentido corriente, como un número o un cálculo. Pero la medida del poetizar es la divinidad y, por tanto, Dios.

Se pregunta Heidegger, entonces, por el "quién" de Dios, algo obviamente muy difícil. Se ve más posible contestar el "qué" de Dios. Para ello contamos con los versos del poeta:

¿Qué es Dios?, desconocido, sin embargo

Lleno de cualidades suyas es el semblante

Del cielo. Los rayos y también

la ira de un Dios. Algo cuanto más 
Invisible es, se destina en lo extraño... (citado en Heidegger, 1960, p. 87)

Lo que permanece extraño a Dios esto es lo confiado al hombre, o sea todo lo que hay en el cielo y debajo del cielo sobre la tierra, lo que brilla, más también empalidece y obscurece. "Todo esto es lo confiado al hombre, pero extraño a Dios, para que allí permanezca protegido como lo desconocido" (Heidegger, 1960 p. 88).

El poeta, empero, clama en la palabra cantante toda claridad de las miradas del cielo(...) y allí trae lo clamado para iluminar y resonar. Solamente que el poeta no describe, si él es poeta, el simple aparecer del cielo y de la tierra (...) el poeta clama en las miradas del cielo Aquello que en el desvelarse deja aparecer precisamente lo que se-oculta, a saber, como lo que -se-oculta. El poeta clama lo extraño en las confiadas apariencias como aquello en lo cual se destina lo invisible, para seguir siendo lo que es: desconocido.

El poeta poetiza sólo si toma la medida [Dios] cuando él dice de tal manera las miradas del cielo, que él se somete a sus apariciones como el extraño en el cual se 'destina' el Dios desconocido" (Heidegger, 1960 p. 88).

El poeta toma aquella misteriosa medida en el semblante del cielo, no como nosotros, y por eso habla en imágenes, que no son simples fantasías; son imaginaciones en cuanto inclusiones visibles de lo extraño, que hay en la mirada de lo confiado al hombre en esta tierra. Es en es la extrañeza que se anuncia Dios como proximidad no dejada.

Pleno de mérito, más poéticamente (...)

"...Pero no es más pura

La sombra de la noche con las estrellas

Si así pudiera yo decir, tal como

El hombre, a quien se le llama imagen de la divinidad. (citado en Heidegger, 1960, p. 88).

¿Hay una medida sobre la tierra?

...'No hay Ninguna' (citado en Heidegger, 1960, p. 89).

No la hay. Con esta frase ("sobre la tierra") Holderlin se refiere al habitar en la tierra y en este habitar se "deja a la tierra ser en cuanto tierra" (Heidegger, 1960, p. 89). "El hombre no habita en cuanto él únicamente instala su detención sobre la tierra, debajo del cielo, cuidando el crecimiento como labrador-constructor..." (Heidegger, 1960, p. 89). La medida del poetizar se

...destina como lo extraño, en el cual el invisible se guarda en lo confiado de la mirada del cielo. Es por eso que la medida es el carácter esencial, del cielo (...) El brillo del cielo es el levante y el ocaso del crepúsculo que alberga todo lo anunciable. (Heidegger, 1960 p. 89)

El habitar poético acontece cuando el poetizar se realiza y despliega su esencia, es decir, como la toma de medida de todo medir. El poetizar lleva al habitar del hombre a su esencia, no cuando queda detenido sobre la tierra, debajo del cielo, sino sólo cuando construye tomando en cuenta la medida poética, es decir, cuando son los poetas quienes toman la medida para la arquitectura y para las estructuras del habitar. "El poetizar es el originario dejar habitar". (Heidegger, 1960 p. 89). 
Poetizar edifica, entonces, la esencia del habitar. Nosotros no habitamos poéticamente, sino del todo impoéticamente. ¿Es entonces la palabra del poeta, mentira? No, porque sólo se puede ser impoético porque el habitar es poético, tal como se puede quedar sordo porque tenemos oídos, como señala el filósofo en su ensayo Serenidad. (Heiddeger, 1983). Puede ser que nuestro habitar impoético provenga de una incapacidad para tomar la medida, o de un exceso de calcular y medir. Experimentaremos nuestro habitar impoético sólo si tocamos y cuidamos en cada uno de nosotros la dimensión de lo poético. Por eso el poetizar no se realiza todo el tiempo. ¿Cuándo y cuánto dura?

...Mientras la pureza, la amabilidad aún

Perduren junto al corazón, no se mide

Desventuradamente el hombre

Con la divinidad... (Citado en Heiddeger, 1960, pp. 90 y 91)

"Junto al corazón" (Heiddeger, 1960, p. 91), una expresión favorita del Hölderlin: "...haber llegado a la esencia habitante del hombre, haber llegado al corazón como apelación de la medida, para q ésta tenga en cuenta la medida" (Heiddeger, 1960, p. 91). "Entonces el hombre habita humanamente sobre esta tierra" (Heiddeger, 1960, p. 91).

\section{Conclusión}

En Ser y tiempo Heidegger (1998) plantea la existencia auténtica, la cual asume el ser como propio, frente al impropio, en cuanto se hace cargo de su condición de arrojado, su tener que resolver su existencia decidiéndose en una u otra dirección y el estar vuelto hacia la muerte asumiéndola en cada resolución como un paso a un final que se revela como nada, es decir, o sea, al Dasein se le cierran sus posibilidades. En la existencia propia el Dasein es llamado por una voz que procede desde sí mismo interpelándolo a vivir en concordancia con el ser, asumiendo su finitud y la angustia que ésta conlleva. En los textos poéticos la existencia propia del poeta consiste en vivir en vinculación con el Ser a través del lenguaje que nombra la esencia de las cosas y del diálogo en que se realiza el ser histórico del hombre. La vocación del poeta es transmitir a su pueblo, desconocedor del verdadero habitar, el mensaje de los dioses, recibido en signos que él descifra y a los cuales él es receptivo. Asimismo, él relata al pueblo las leyendas milenarias en que los dioses se manifiestan. El poeta es, entonces, un extraño en medio de una época en que el hombre habita impoéticamente, desvinculado del Ser, permitiendo así la fuga de los dioses. ¿Podrá la humanidad esperar al Dios por venir?

\section{Referencias Bibliográficas}

Heidegger, M. (1944). Holderlin y la Esencia de la Poesía. Revista Universidad Pontificia Bolivariana, 11(38), 13-25. https://bit.ly/38LDtjW

Heidegger, M. (1960). "... Poeticamente habita el hombre...". Revista de Filosofía, 7(1-2), pp. 77-91. https://bit.ly/380k8we

Heidegger, M. (1998) Ser y tiempo (J. E. Rivera, Trad.). Santiago: Universitaria. 
Heidegger, M. (1983). Serenidad.. Santigo: Universidad de Chile, Facultad de Filosofía.

Rivera, J. E: (2006). Heráclito el esplendente. Santiago: Brickle.

\section{Para citar este artículo bajo Norma APA 7a ed.}

Stuven Vattier, M. T. (2020). Entre la filosofía y la poesía:

Heidegger y Hölderlin. Cuadernos de teología - Universidad

Católica del Norte (En línea), 12, e4575,

https://doi.org/10.22199/issn.0719-8175-2020-0013

DOI

Copyright del articulo: (C2020 Teresa Stuven

(cc) BY

Este es un artículo de acceso abierto, bajo licencia Creative Commons BY 4.0. 